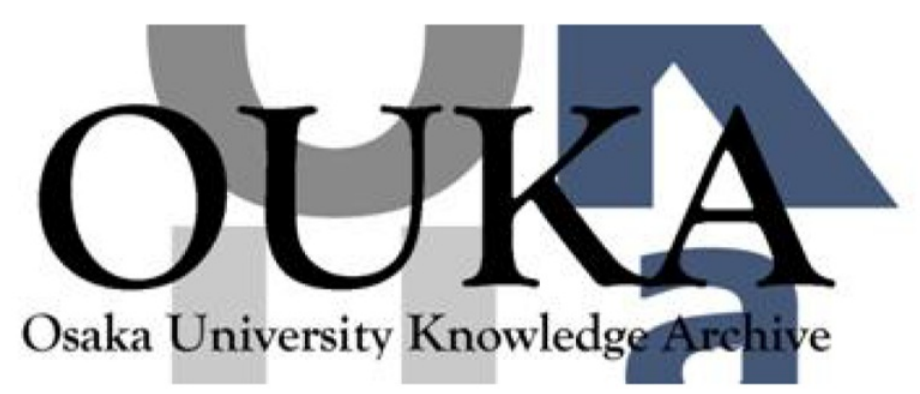

\begin{tabular}{|c|l|}
\hline Title & $\begin{array}{l}\text { Measurement of Dielectric Response of 1MC1EPOPB } \\
\text { and 1BC1EPOPB Ferroelectric Liquid Crystals }\end{array}$ \\
\hline Author(s) & $\begin{array}{l}\text { Yoshino, Katsumi; Ozaki, Masanori; Srivastava, } \\
\text { K. et al. }\end{array}$ \\
\hline Citation & $\begin{array}{l}\text { IEEE Transactions on Dielectrics and Electrical } \\
\text { Insulation. 11(1) p. 179-p. 183 }\end{array}$ \\
\hline Issue Date & $2004-02$ \\
\hline oaire:version & VoR \\
\hline URL & $\begin{array}{l}\text { https://hdl. handle. net/11094/3316 } \\
\text { ब2004 IEEE. Personal use of this material is } \\
\text { permitted. However, permission to } \\
\text { reprint/republish this material for advertising } \\
\text { or promotional purposes or for creating new } \\
\text { collective works for resale or redistribution } \\
\text { to servers or lists, or to reuse any } \\
\text { copyrighted component of this work in other } \\
\text { works must be obtained from the IEEE. }\end{array}$ \\
\hline rights \\
\hline Note & \begin{tabular}{l} 
\\
\hline
\end{tabular} \\
\hline
\end{tabular}

Osaka University Knowledge Archive : OUKA

https://ir. Library. osaka-u. ac. jp/

Osaka University 


\title{
Measurement of Dielectric Response of 1MC1EPOPB and 1BC1EPOPB Ferroelectric Liquid Crystals
}

\author{
K. Yoshino, M. Ozaki \\ Department of Electronics Engineering \\ Osaka University, 2-1 Yamada-oka \\ Osaka, 565-0871, Japan
}

\author{
K. Srivastava, M. Johri and G. K. Johri \\ Department of Physics and Electronics, D.A-V. College \\ 119/91, Darshanpurwa, Kanpur 208012, India
}

\begin{abstract}
Dielectric measurements have been carried out using an impedance analyzer for two ferroelectric liquid crystals R-4' (1-methoxycarbonyl-1-ethoxy) phenyl 4-(4-octyloxy phenyl) benzoate (1MC1EPOPB) and R-4' (1-butoxycarbonyl-1-ethoxy) phenyl 4(4-octyloxy phenyl) benzoate (1BC1EPOPB). The two types have large spontaneous polarization, $+1700 \mu \mathrm{C} / \mathrm{m}^{2}$ for $1 \mathrm{MC1EPOPB}$ and $+2400 \mu \mathrm{C} / \mathrm{m}^{2}$ for 1BC1EPOPB. The permittivity and dielectric loss have been measured at different temperatures in the range $343.0 \mathrm{~K}$ to $383.0 \mathrm{~K}$ for $1 \mathrm{MC1EPOPB}$ and $318.0 \mathrm{~K}$ to 353.0 $\mathrm{K}$ for 1BC1EPOPB in the frequency range $2 \mathrm{~Hz}$ to $2 \mathrm{MHz}$. Both of the ferroelectric liquid crystals, 1MC1EPOPB and 1BC1EPOPB show a new phase smectic $X$ along with smectic $\mathrm{C}^{*}$ and smectic $A$ phases. The work reported in this paper is new and is very useful in understanding their application in switching devices.

Index Terms - Dielectric properties, ferroelectric liquid crystal, dielectric permittivity, dielectric loss, phase transition, dielectric relaxation, spontaneous polarization, impedance analyzer, interaction, switching devices.
\end{abstract}

\section{INTRODUCTION}

$\mathrm{T}$ HE dielectric spectroscopic technique [1-4] has been used by various workers for the study of systems in different phases. This method [5-6] has been found to be one of the best ones to make measurement of permittivity and dielectric loss with high accuracy and sensitivity. In this paper we have chosen R-4' (1-methoxycarbonyl-1-ethoxy) phenyl 4-(4-octyloxy phenyl) benzoate (1MC1EPOPB) and R-4' (1-butoxycarbonyl-1-ethoxy) phenyl 4-(4-octyloxy phenyl) benzoate (1BC1EPOPB), smectic ferroelectric liquid crystals, which are relatively of large spontaneous polarization $+1700 \mu \mathrm{C} / \mathrm{cm}^{2}$ and $+2400 \mu \mathrm{C} / \mathrm{cm}^{2}$ respectively. These ferroelectric liquid crystals were synthesized by Yoshino et al. [7-8]. The dielectric spectroscopic technique has been used to measure permittivity $\left(\epsilon_{\perp}^{\prime}\right)$ and dielectric loss $\left(\epsilon_{\perp}^{\prime \prime}\right)$ at frequencies 2

Manuscript received on 1 December 2003, in final form 21 July 2003.
$\mathrm{Hz}$ to $2 \mathrm{MHz}$ in the temperature range $343.0 \mathrm{~K}$ to $383.0 \mathrm{~K}$ for $1 \mathrm{MC} 1 \mathrm{EPOPB}$ and $318.0 \mathrm{~K}$ to $348.0 \mathrm{~K}$ for $1 \mathrm{BC} 1 \mathrm{EPOPB}$ using planar aligned cells. The variations of permittivity and dielectric loss in the selected range of frequencies and temperatures are analyzed. The variations of dielectric strength $(\Delta \epsilon)$ and relaxation frequencies $\left(f_{r}\right)$ in the corresponding temperature ranges are also studied for the two ferroelectric liquid crystals under study.

\section{EXPERIMENTAL DETAILS}

The samples of 1MC1EPOPB and 1BC1EPOPB, synthesized by Yoshino et al [7-8], have the following structures

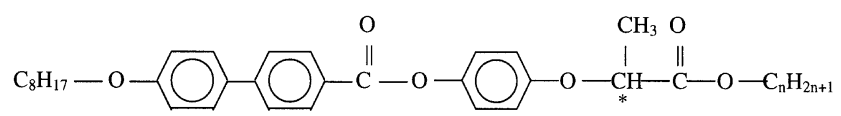




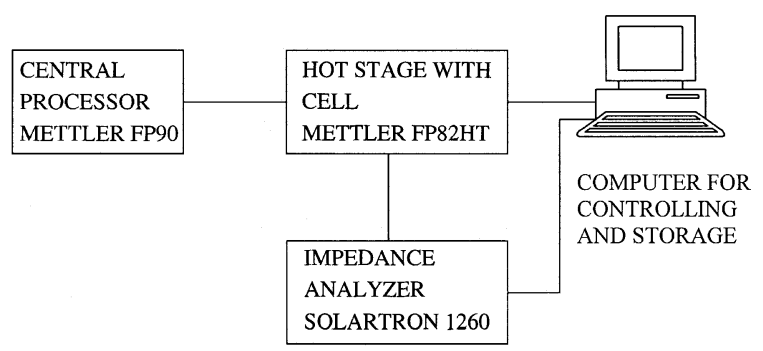

Figure 1. Block diagram of experimental arrangement with Impedance Analyzer, Hot stage, Central Processor and Computer for dielectric measurements.

$\mathrm{n}=11 \mathrm{MC1EPOPB}$ and $\mathrm{n}=4$ 1BC1EPOPB

The two samples have following phase sequence 1MC1EPOPB:

Crystal $\stackrel{318.9 \mathrm{~K}}{\longleftarrow} \mathrm{Sm} \mathrm{X} \stackrel{354.8 \mathrm{~K}}{\longleftarrow} \mathrm{Sm} \mathrm{C}^{*} \stackrel{370.7 \mathrm{~K}}{\longleftarrow}$
$\mathrm{Sm} \mathrm{A} \stackrel{420.9 \mathrm{~K}}{\longleftarrow}$ Isotropic

1BC1EPOPB:

Crystal $\stackrel{280.8 \mathrm{~K}}{\longleftarrow} \mathrm{Sm} \mathrm{X} \stackrel{329.1 \mathrm{~K}}{\longleftarrow} \mathrm{Sm} \mathrm{C}^{*} \stackrel{339.2 \mathrm{~K}}{\longleftarrow}$
$\mathrm{Sm} \mathrm{A} \stackrel{392.2 \mathrm{~K}}{\longleftarrow}$ Isotropic

The block diagram of the apparatus used with name of each block marked is shown in Figure 1. The experimental arrangement for dielectric technique consists of an impedance analyzer model Solartron $1260(10 \mu \mathrm{Hz}$ to 32 $\mathrm{MHz}$ ), hot stage model METTLER FP82HT and central processing unit model METTLER FP90 connected with a computer. The sample is filled in a planar oriented cell in isotropic phase using the principle of capillary action. The planar oriented cell with thickness $48 \mu \mathrm{m}$ is used for $1 \mathrm{MC} 1 \mathrm{EPOPB}$ and $33 \mu \mathrm{m}$ for 1BC1EPOPB for dispersion studies. The uncertainty in the measurement is $\pm 100 \mathrm{ppm}$ with stability of $\pm 10 \mathrm{ppm}$ in $24 \mathrm{~h}$ within $1 \mathrm{~K}$. The resolution varies from $10 \mu \mathrm{Hz}$ to $1 \mathrm{~Hz}$. The planar oriented cell filled with material is kept in the hot stage. The computer program has been developed to run at different points of equal intervals in the log frequency scale for the measurement of capacitance in parallel to the conductance. We have set the range of the frequency measurements for the two samples under investigation with the temperature variation in the steps of 0.2 to $5 \mathrm{~K}$ near the phase transition and away from it. The impedance analyzer has adjustable oscillator signal but the signal is kept at $1 \mathrm{~V}$ in different runs in the present work. The central processing unit model METTLER FP90 is used to control the temperature of the hot stage.

\section{RESULTS AND DISCUSSIONS}

We have illustrated the variations of dielectric permittivity and dielectric loss as a function of frequency in $2 \mathrm{~d}$ at middle temperature of each phase for $1 \mathrm{MC} 1 \mathrm{EPOPB}$ and
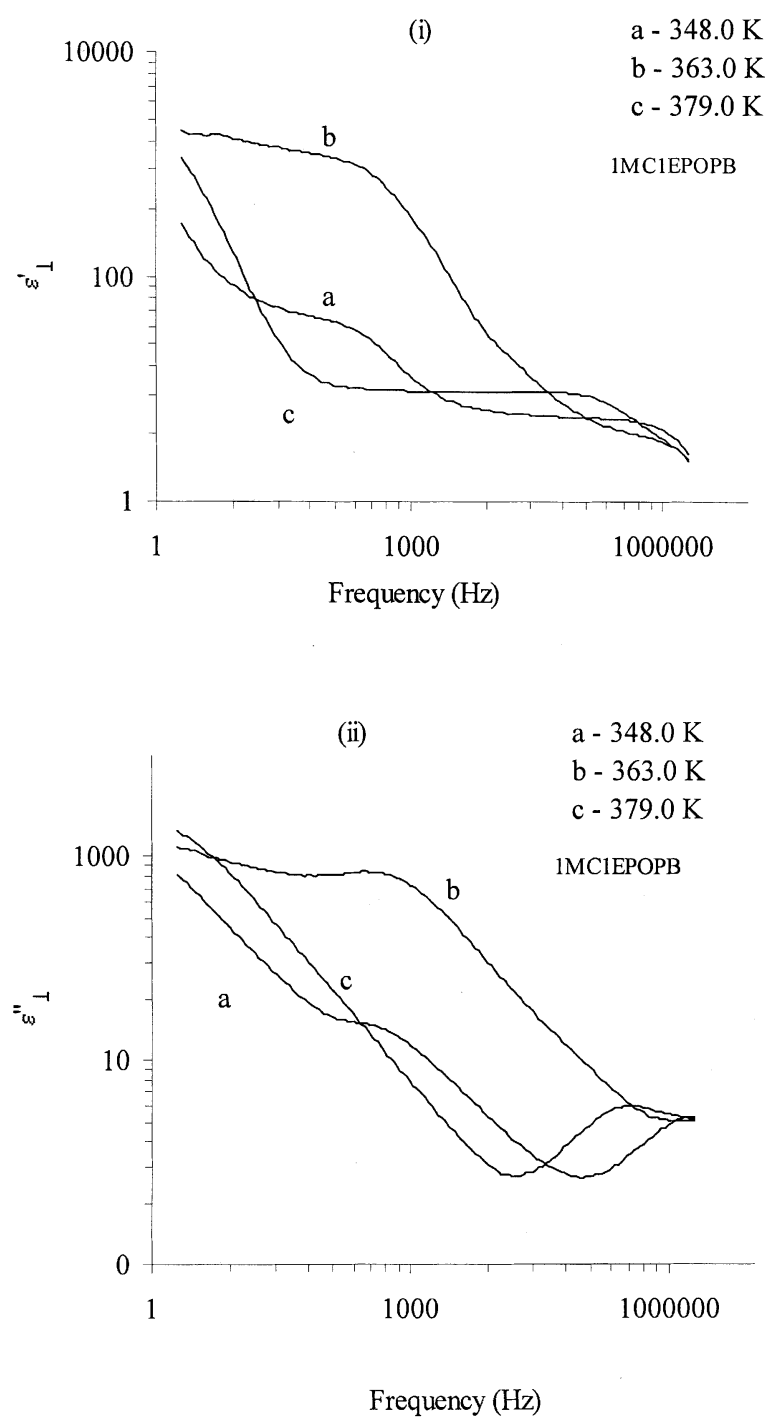

Figure 2. i, dielectric permittivity $\left(\epsilon_{\perp}^{\prime}\right)$; ii, dielectric loss $\left(\epsilon_{\perp}^{\prime \prime}\right)$ for $1 \mathrm{MC1EPOPB}$ at (a) $348.0 \mathrm{~K}$; (b) $363.0 \mathrm{~K}$ and (c) $379.0 \mathrm{~K}$.

1BC1EPOPB in Figures 2 and 3. Although similar characteristics may be seen at all other temperatures except in the case of smectic $A$ and smectic $X$ where the peak shifts towards the lower frequency as the temperature decreases. The variation of relaxation frequency $\left(f_{r}\right)$ and dielectric strength $(\Delta \epsilon)$ with temperature for $1 \mathrm{MC1EPOPB}$ and 1BC1EPOPB are plotted in Figures 4 and 5 , respectively.

An examination of Figures 2 and 3 gives that the Soft mode occurs for smectic A phase above $100 \mathrm{kHz}$ for $1 \mathrm{MC1EPOPB}$ as well as for 1BC1EPOPB showing loss peak around $200 \mathrm{kHz}$ for $1 \mathrm{MC} 1 \mathrm{EPOPB}$ at $379 \mathrm{~K}$ and 100 $\mathrm{kHz}$ for $1 \mathrm{BC} 1 \mathrm{EPOPB}$ at $344 \mathrm{~K}$. Figures 2 and 3 also illustrate that the Goldstone mode originates for smectic $\mathrm{C}^{*}$ phase below $1 \mathrm{kHz}$ for $1 \mathrm{MC1EPOPB}$ and $500 \mathrm{kHz}$ for $1 \mathrm{BC} 1 \mathrm{EPOPB}$. The loss peaks are occurring around 0.3 $\mathrm{kHz}$ for $1 \mathrm{MC1EPOPB}$ at $363 \mathrm{~K}$ and $0.5 \mathrm{kHz}$ for $1 \mathrm{BC} 1 \mathrm{EPOPB}$ at $333 \mathrm{~K}$. The relaxation process shown in 


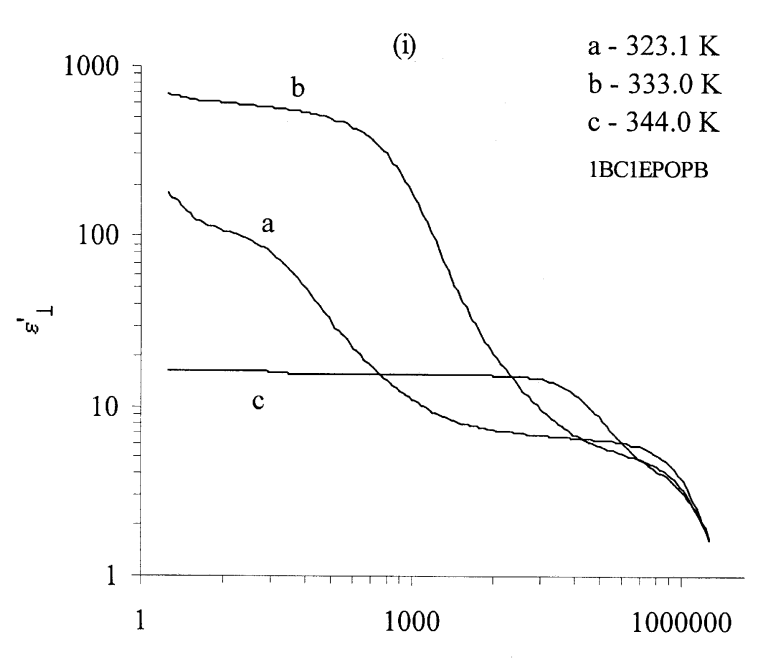

Frequency $(\mathrm{Hz})$

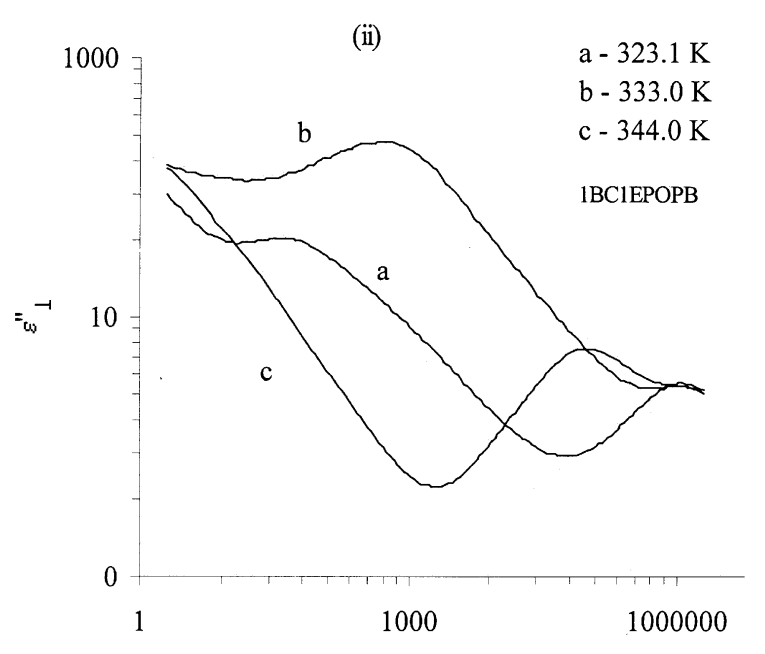

Frequency $(\mathrm{Hz})$

Figure 3. i, dielectric permittivity $\left(\epsilon_{\perp}^{\prime}\right)$; ii, dielectric loss $\left(\epsilon_{\perp}^{\prime \prime}\right)$ for $1 \mathrm{BC} 1 \mathrm{EPOPB}$ at (a) $323.1 \mathrm{~K}$; (b) $333.0 \mathrm{~K}$ and (c) $344.0 \mathrm{~K}$.

Figures 2 and 3 in smectic $\mathrm{X}$ phase is below $10 \mathrm{kHz}$ for $1 \mathrm{MC} 1 \mathrm{EPOPB}$ and $0.4 \mathrm{kHz}$ for $1 \mathrm{BC} 1 \mathrm{EPOPB}$ giving loss

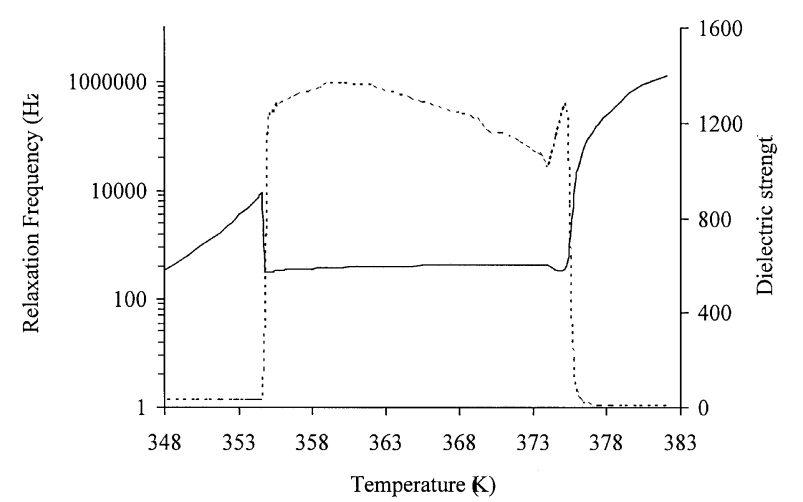

Figure 4. Variation of relaxation frequency $\left(f_{r}\right)\left(\_\right.$) and dielectric strength $(\Delta \epsilon)(----)$ with temperature for 1MC1EPOPB.

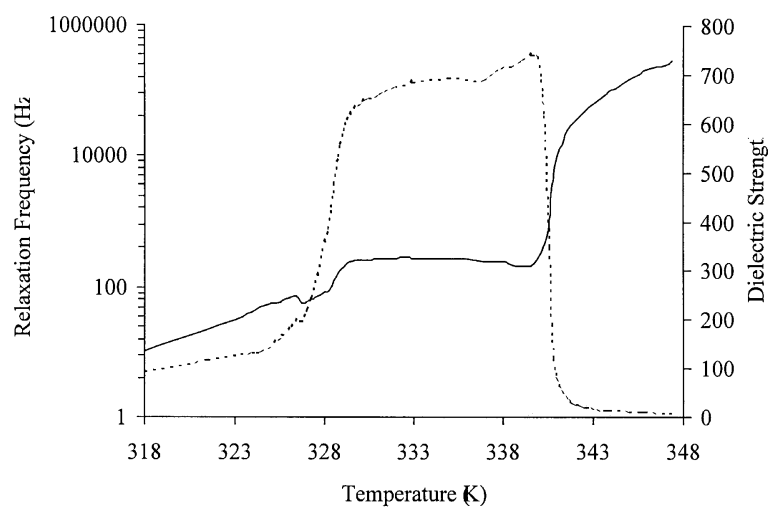

Figure 5. Variation of relaxation frequency $\left(f_{r}\right)\left(\_\right)$and dielectric strength $(\Delta \epsilon)(----)$ with temperature for 1BC1EPOPB.

peak at $0.3 \mathrm{kHz}$ for $1 \mathrm{MC} 1 \mathrm{EPOPB}$ at $348 \mathrm{~K}$ and $0.04 \mathrm{kHz}$ for $1 \mathrm{BC} 1 \mathrm{EPOPB}$ at $323.1 \mathrm{~K}$. We expect Soft mode for smectic $\mathrm{X}$ as the characteristics of smectic A and smectic $\mathrm{X}$ seems to be similar in variation.

The observed data of dielectric permittivity $\left(\epsilon_{\perp}^{\prime}\right)$ and dielectric loss as a function of frequency in the log-log plot in approximately the mid temperatures of smectic A ( $379 \mathrm{~K})$, smectic $\mathrm{C}^{*}(363 \mathrm{~K})$ and smectic $\mathrm{X}(348 \mathrm{~K})$ phases for 1MC1EPOPB are shown in Figures $2 \mathrm{i}$ and 2ii, respectively. The log-log plots of dielectric permittivity and dielectric loss at approximately the mid temperature of smectic A $(344.0 \mathrm{~K})$, smectic C* $(333.0 \mathrm{~K})$ and smectic X $(323.1 \mathrm{~K})$ phases for 1BC1EPOPB are given in Figures $3 \mathrm{i}$ and 3ii, respectively. Figure $2 \mathrm{i}$ makes it evident that at very large frequency of $2000 \mathrm{kHz}$ the permittivity plots with frequency for $379.0 \mathrm{~K}, 363.0 \mathrm{~K}$ and $348.0 \mathrm{~K}$ coincide giving a permittivity independent of temperature. The plots of $\epsilon_{\perp}^{\prime}$ for $379.0 \mathrm{~K}$ and $363.0 \mathrm{~K}$ have one point of intersection with $\epsilon_{\perp}^{\prime}=9.54$ at $42.4 \mathrm{kHz}$. The permittivity plot for smectic $\mathrm{X}$ at $348.0 \mathrm{~K}$ has 3 points of intersections with the permittivity plot for smectic $\mathrm{A}$ at $379.0 \mathrm{~K}$ around $409 \mathrm{kHz}, 1.59 \mathrm{kHz}$ and $0.0152 \mathrm{kHz}$. The variation of $\epsilon_{\perp}^{\prime}$ with frequency for smectic $\mathrm{X}$ at $348.0 \mathrm{~K}$ has one common point with the same plot for smectic $\mathrm{C}^{*}$ at $363.0 \mathrm{~K}$ at about $118 \mathrm{kHz}$. The variation of $\epsilon_{\perp}^{\prime}$ with frequency for smectic $\mathrm{A}$ at $379.0 \mathrm{~K}$ shows that the decrease in the value of $\epsilon_{\perp}^{\prime}$ is very sharp and almost linear from 1120 at 0.002 $\mathrm{kHz}$ to 16.1 at $0.047 \mathrm{kHz}$ as the frequency is increased and then it is almost independent of frequency till 9.38 at 66.8 $\mathrm{kHz}$. On further increase in frequency it decreases again to the value 2.3 at $2000 \mathrm{kHz}$. The plot of $\epsilon_{\perp}^{\prime}$ decreases from 1960 at $0.002 \mathrm{kHz}$ to 922 at $0.259 \mathrm{kHz}$ and then decreases to 2.3 at $2000 \mathrm{kHz}$ much faster for smectic $\mathrm{X}$ at $363.0 \mathrm{~K}$ as the frequency increases. The plot of permittivity for smectic X has the smallest value 290 of $\epsilon_{\perp}^{\prime}$ out of the three phases under investigation at $0.002 \mathrm{kHz}$.

Figure 2ii shows that the plots of dielectric loss with frequency for smectic $\mathrm{A}$ at $379.0 \mathrm{~K}$, smectic $\mathrm{C}^{*}$ at $363.0 \mathrm{~K}$ 
and smectic $\mathrm{X}$ at $348.0 \mathrm{~K}$ have a common value about 2.67 at $2000 \mathrm{kHz}$. The plot of $\epsilon_{\perp}^{\prime \prime}$ for smectic A intersects the plot for smectic $\mathrm{C}^{*}$ around at $0.004 \mathrm{kHz}$ and $409 \mathrm{kHz}$. It also has two points of intersection with the similar plot for smectic $\mathrm{X}$ at about $0.206 \mathrm{kHz}$ and $33.8 \mathrm{kHz}$. The plot of dielectric loss for smectic A has the value of 1790 at 0.002 $\mathrm{kHz}$, which is the largest of the three plots. As the frequency is decreased the value of dielectric loss decreases linearly till 0.741 at $17.1 \mathrm{kHz}$ from there it changes the sign of the slope and starts rising to 3.56 at $365 \mathrm{kHz}$ and then again starts decreasing on further increase in frequency till $2000 \mathrm{kHz}$. The similar plot for smectic X decreases from 663 at $0.002 \mathrm{kHz}$ to 0.716 at $105 \mathrm{kHz}$ and then the slope is reversed and the dielectric loss starts increasing with frequency till $2000 \mathrm{kHz}$.

From Figure $3 \mathrm{i}$ it is clear that the permittivity plots with frequency for $344.0 \mathrm{~K}, 333.0 \mathrm{~K}$ and $323.1 \mathrm{~K}$ coincide giving a permittivity independent of temperature at very large frequency of $2000 \mathrm{kHz}$. The curve for smectic $\mathrm{C}^{*}$ and smectic $\mathrm{X}$ have one more point of intersection at about $83.7 \mathrm{kHz}$ while the curves for smectic $\mathrm{C}^{*}$ and smectic A intersect around $10 \mathrm{kHz}$. Also there are two points of intersection for smectic A and smectic $\mathrm{X}$ at about $165 \mathrm{kHz}$ and $0.400 \mathrm{kHz}$. The smectic $\mathrm{C}^{*}$ has largest value 680.77 of $\epsilon_{\perp}^{\prime}$ out of the three phases under investigation at 0.002 $\mathrm{kHz}$. As the frequency increases the value of $\epsilon_{\perp}^{\prime}$ decreases from 680.77 to 365.1 at $0.363 \mathrm{kHz}$ slowly and then the variation in the value of $\epsilon_{\perp}^{\prime}$ is steeper. The smectic X has the value of $\epsilon_{\perp}^{\prime}=177.11$ at $0.002 \mathrm{kHz}$ and decreases to 96.25 at $0.015 \mathrm{kHz}$ with increase in frequency. As the frequency is further increased from $0.015 \mathrm{kHz}$, the $\epsilon_{\perp}^{\prime}$ falls sharply to 7.76 at $4.4 \mathrm{kHz}$ and then it is almost independent of frequency up to $260 \mathrm{kHz}$ and hereafter it decreases at increasing rate. The permittity plot with frequency for smectic A has nearly constant value $\epsilon_{\perp}^{\prime}=16.42$ up to $22.7 \mathrm{kHz}$ before it has sharp decrease.

Figure 3ii reveals that at $2 \mathrm{MHz}$ all the three curves for variation of $\epsilon_{\perp}^{\prime \prime}$ with frequency corresponding to smectic $\mathrm{A}$, smectic $\mathrm{C}^{*}$ and smectic $\mathrm{X}$ have nearly equal values. The plot, showing the changes in $\epsilon_{\perp}^{\prime \prime}$ with frequency for smectic $\mathrm{A}$ at $344.0 \mathrm{~K}$, intersects the similar curves for smectic $\mathrm{C}^{*}$ at $333.0 \mathrm{~K}$ and smectic $\mathrm{X}$ at $323.1 \mathrm{~K}$ around 85 $\mathrm{kHz}$ and $10 \mathrm{kHz}$ respectively in log-log plot. But smectic $\mathrm{C}^{*}$ and smectic $\mathrm{X}$ curves do not intersect each other within the frequency range from $2 \mathrm{~Hz}$ to $2 \mathrm{MHz}$ of measurement. The smectic A curve for dielectric loss with frequency decreases with nearly a constant slope from 140 at $2 \mathrm{~Hz}$ to 0.65 at $880 \mathrm{~Hz}$ and attains a minima with $\epsilon_{\perp}^{\prime \prime}=0.49$ at 1.9 $\mathrm{kHz}$. The lowest loss amounts to least possibility of dispersion for smectic A phase at $344 \mathrm{~K}$. On further increase in frequency the direction of slope reverses and dielectric loss increases with constant slope to 4.09 at $40.2 \mathrm{kHz}$ and attains a peak at $104 \mathrm{kHz}$ having the value $\epsilon_{\perp}^{\prime \prime}=5.82$ after which the slope again reverses its direction. The curve for smectic $\mathrm{C}^{*}$ has the value $\epsilon_{\perp}^{\prime \prime}=149.58$ at $2 \mathrm{~Hz}$ and has very slow decrease to 114.02 at $14 \mathrm{~Hz}$ with the increase in frequency. Now it starts increasing and after attaining a maximum value $\epsilon_{\perp}^{\prime \prime}=229$ at $511 \mathrm{~Hz}$ it decreases. After 1 $\mathrm{kHz}$ the $\epsilon_{\perp}^{\prime \prime}$ decays with a constant slope up to $232 \mathrm{kHz}$ and then it is nearly constant. The smectic X curve has value 88.2 for $\epsilon_{\perp}^{\prime \prime}$ at $2 \mathrm{~Hz}$ and then decreases with the increase in frequency up to 37.5 at $12 \mathrm{~Hz}$ and after that small variations with a constant slope are found. This slope changes sign after $59.6 \mathrm{kHz}$.

The change of relaxation frequency $\left(f_{r}\right)$ and dielectric strength $(\Delta \epsilon)$ when the structure is transformed from the twisted (smectic A) to helical one (smectic $\mathrm{C}^{*}$ ), is seen in Figures 4 and 5. On cooling, for both the samples the change of structure is manifested by a jump down in $f_{r}$ and jump up in $\Delta \epsilon$. In smectic $\mathrm{C}^{*}$ the molecules are tilted with respect to the smectic layer normal direction giving helical structure while in the smectic A phase they are along the layer normal direction and show twisted structure. Thus in the vicinity of smectic A to smectic $\mathrm{C}^{*}$ transition, thermal fluctuations cause fluctuations in the amplitude of either long-range (smectic $\mathrm{C}^{*}$ ) or local (smectic A) tilt. But in both the phases, an associated elastic constant controls the magnitude of these fluctuations. This elastic constant softens on approaching the transition and therefore, the amplitude of fluctuation increases. This in turn increases the contributions to the dielectric strength and an accompanying decrease in the relaxation frequency and therefore $\Delta \epsilon$ has a maximum and $f_{r}$ a minimum at the smectic $\mathrm{A}$ to smectic $\mathrm{C}^{*}$ transition. While at the smectic $\mathrm{C}^{*}$ to smectic $\mathrm{X}$ transition $\Delta \epsilon$ jumps down and $f_{r}$ jumps up. From Figures 4 and 5 it is evident that the dielectric strength is largest in the smectic $\mathrm{C}^{*}$ phase and decreases sharply in smectic $\mathrm{X}$ and smectic A phases for both the samples. The relaxation frequency is maximum in the smectic A phase but it is almost constant for smectic $\mathrm{C}^{*}$ in both the samples under study.

\section{CONCLUSION}

$T_{1}$ HE Goldstone mode and Soft mode gives loss peaks around frequencies $0.3 \mathrm{kHz}$ and $200 \mathrm{kHz}$ for $1 \mathrm{MC1EPOPB}$ at $379.0 \mathrm{~K}$ and $363.0 \mathrm{~K}$ respectively while $0.5 \mathrm{kHz}$ and $100 \mathrm{kHz}$ for $1 \mathrm{BC} 1 \mathrm{EPOPB}$ at $333.0 \mathrm{~K}$ and $344.0 \mathrm{~K}$ respectively. Our observations indicate that smectic $\mathrm{X}$ phase in the temperature range $322.9 \mathrm{~K}$ to $354.8 \mathrm{~K}$ for $1 \mathrm{MC} 1 \mathrm{EPOPB}$ and $280.8 \mathrm{~K}$ to $329.1 \mathrm{~K}$ for $1 \mathrm{BC} 1 \mathrm{EPOPB}$ has the same trend of variations in both the systems chosen for all the parameters $\left(\epsilon_{\perp}^{\prime}, \epsilon_{\perp}^{\prime \prime}, f_{r}\right.$ and $\left.\Delta \epsilon\right)$. We have also observed that different phases coincide at some frequency for both the systems. Further we have concluded that disorder increases for smectic $\mathrm{A}$ and smectic $\mathrm{X}$ with the rise in temperature while more ordered state is found for smectic $\mathrm{C}^{*}$ for both the systems at almost all the temperatures. The measurements reported in this paper are fruitful for understanding molecular collisions, structure 
and change of the phase as a function of temperature and dielectric behaviour at different frequencies. These observations for smectic ferroelectric liquid crystals considered may help in understanding its applications in fabricating fast switching devices.

\section{ACKNOWLEDGMENT}

The authors feel highly obliged to Prof. S. Chandrasekhar, CLCR, Bangalore, India, for providing infrastructure facilities of his institute in taking measurements.

\section{REFERENCES}

[1] C. J. F. Böttcher and P. Brodewijk, Theory of Electrical Polarization, Elsevier, Vol. 2, 1978

[2] N. E. Hill, W. E.Vaughan, A. H. Price and M. Davies, Dielectric Properties and Molecular Behaviour, Van Nostrand Reinhold Co., London, 1969.

[3] G. K. Johri, M. Johri, N. Saxena and J. A. Roberts, "Dielectric Response and Phase Transition Studies of p-Azoxy anisol and 1-1'-Diacetyl Ferrocene in Pure and Binary Mixtures", Mol. Mat., Vol. 5, pp. 63-77, 1995.

[4] P. J. Collings and J. S. Patel, Handbook of Liquid Crystal Research, Oxford University Press, New York, Oxford, 1997.

[5] A. M. Biradar, D. Kilian, S. Wrobel and W. Haase, "A Sub-hertz Frequency Dielectric Relaxation Process in a Ferroelectric Liquid Crystal Materials", Liquid Crystals, Vol. 27, pp. 225-231, 2000.

[6] G. K. Johri, K. Srivastava, M. Johri and K. Yoshino, "Dielectric and Phase Transition Studies of 1MC1EPOPB Ferroelectric Liquid Crystal”, Mol. Cryst. Liq. Cryst., Vol. 366, pp. 673-681, 2001.

[7] K. Yoshino, M. Ozaki, K. Nakao, H. Taniguchi, N. Yamasaki and K. Satoh, "Magnitude and Direction of the Spontaneous Polarization of Ferroelectric Liquid Crystals with Several Bond Moments", Liquid Crystals, Vol. 5, pp. 1203-1211, 1989.

[8] K. Yoshino, M. Ozaki, H. Taniguchi, M. Ito, K. Satoh, N. Yamasaki and T. Kitazume, "Effect of the Molecular Structure of the Chiral Part of Spontaneous Polarization and Dielectric Properties of Ferroelectric Liquid Crystals", Jpn. J. Appl. Phys., Vol. 26, pp. L1558-1560, 1987.

This paper is based on a presentation given at the IEEE International Conference on Dielectric Liquids, Graz, 7-12 July 2002.

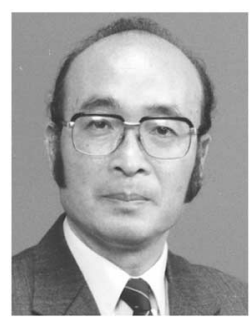

Katsumi Yoshino (SM'96) was born in Shimane, Japan in December 1941. He graduated in 1964 from Osaka University, where he obtained the D.Eng. degree in 1969. In that year, he became a Research Associate in the Department of Electrical Engineering at Osaka University. He was promoted to Assistant Professor, Associate Professor and a Professor in 1972, 1978 and 1988, respectively. He has been engaged in research on organic functional materials, conducting polymers, insulating polymers, liquids and liquid crystals. He is a member of the Institute of Electrical Engineers in Japan (IEEJ), the Institute of Electronics, Information and Communication Engineers (IE ICE), Japan Physical Society, Applied Physical Society and Japanese Liquid Crystal Society (JLCS). He was a Vice-President of the IEEJ and a President of the JLCS. He received the Applied Physics Award, Osaka Scientific Award, Book of the Year Award from the IEEJ, Outstanding Achievement Award from the IEEJ, the IEICE Fellow and the Best Paper Award from the JLCS in 1984, 1990, 1997, 1998, 2001 and 2002, respectively. He has published more than 1000 papers and authored or co-authored more than 33 books.

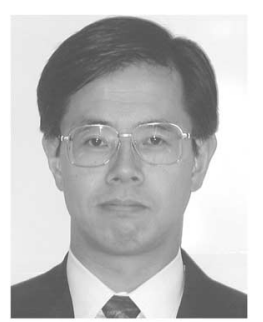

Masanori Ozaki was born in Aichi, Japan in February, 1960. He graduated in 1983 from Osaka University, where he obtained the D.Eng. degree in 1988. He joined the Graduate School of Engineering, Electronic Engineering Department, Osaka University, where he works as an Associate Professor. $\mathrm{He}$ has been engaged in research on liquid crystals, optical functional polymers and photonic crystals. He received the Best $\mathrm{Pa}$ per Award from the Japanese Liquid Crystal Society in 2002. He is a member of the Institute of Electrical Engineers of Japan, the Japan Society of Applied Physics, the Physical Society of Japan, the Japanese Liquid Crystal Society and the Institute of Electronics, Information and Communication Engineers.

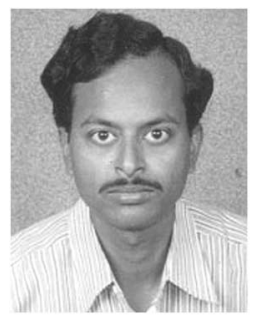

Kuldeep Srivastava was born on 10 August 1975 in Barabanki, Uttar Pradesh, India. He received the M.Sc. degree in electronics in 1997 from Lucknow University and was awarded a Gold medal. Presently he is pursuing research in Ferroelectric Liquid Crystals in D.A-V. college Kanpur, India. He has been working as a Meteorologist-II Trainee in the Meteorological Department in India since 2002.

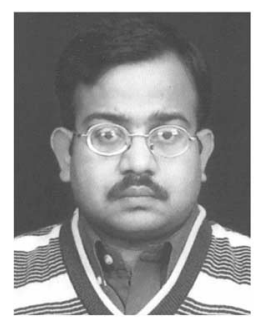

Manoj Johri was born on 1 January 1968 in Kanpur, India. He received the M.Sc. degree in physics in 1989 and a gold medal from Kanpur University (now C.S.J.M. University, Kanpur) and the Ph.D. degree in 1992. His field of interest is molecular collisions and cross-sections study. $\mathrm{He}$ is a Lecturer in the Physics Department in D.A-V. College, Kanpur, India. Currently he is involved in liquid crystals, photonic band gap materials and dielectric studies.

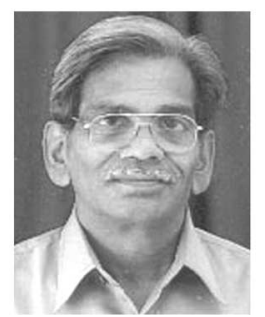

G.K. Johri was born on 1 December 1941 in Etah, India. He received the M.Sc. degree in physics from Agra University, Agra, India in 1963 and the D.Phil. degree from Allahabad University, Allahabad, India in 1977. He developed an independent microwave laboratory at D.A-V. College, Kanpur. He is currently conducting researches in the field of photonic crystals, nanocrystallite semiconductors, ferroelectric liquid crystals and dielectrics. He has published about 250 research papers and supervised 20 Ph.D. students. He was Principal/Director of D.A-V. college, Kanpur, India. Since 1999 Professor Johri has been a member of the International Scientific Advisory Board of IEEE-ICDL. 